\title{
Numerical study on supersonic combustion of hydrogen and its mixture with Ethylene and methane with strut injection
}

\author{
Sugang Ma ${ }^{a, b}$, Fengquan Zhong ${ }^{a, b, *}$, Xinyu Zhang ${ }^{a, b}$ \\ a State Key Laboratory of High Temperature Gas Dynamics, Institute of Mechanics, Chinese Academy of Sciences, \\ Beijing 100190, China \\ ${ }^{\mathrm{b}}$ School of Engineering Science, University of Chinese Academy of Sciences, Beijing 100049, China
}

\section{A R T I C L E I N F O}

Article history:

Received 13 December 2017

Received in revised form

28 February 2018

Accepted 1 March 2018

Available online 23 March 2018

Keywords:

Detached eddy simulation

Reduced kinetic mechanism

Supersonic combustion

Hydrogen

Hydrocarbon

\begin{abstract}
A B S T R A C T
In this paper, supersonic combustion and flow field of hydrogen and its mixture with ethylene and methane from strut injections in a Mach 2 supersonic flow are studied numerically. The fuel mixture of hydrogen, methane and ethylene represents the major products of pyrolysis of hydrocarbon fuels with large molecules such as kerosene as it acts as coolant and flows through cooling channels and absorbs heat. Detached Eddy Simulation with a reduced kinetic mechanism and steady flamelet model are applied to simulate turbulent combustion. The calculated temperature profiles of hydrogen are compared to the experimental results of DLR supersonic combustor for validation of the present numerical method. The supersonic combustion flows associated with shock waves, turbulent vortices and flame structures are studied. With addition of methane and ethylene, the flame zone moves further downstream of the strut and the maximum flow temperature at chamber exit decreases by $200 \mathrm{~K}$. With analysis of total temperature ratios, it is found that combustion efficiency for hydrogen combustion is 0.91 and it decreases to 0.78 for the fuel mixture. The calculation of ignition delay time and flame speed reveals that fuel mixture of hydrogen and hydrocarbons has considerably larger delay time and smaller flame speed, that contributes to the weakened flame zone and lower combustion efficiency.
\end{abstract}

๑ 2018 Hydrogen Energy Publications LLC. Published by Elsevier Ltd. All rights reserved.

\section{Introduction}

Combustion characteristic of hydrocarbons is a key issue in the design of air-breathing engine system. For long-run engines, hydrocarbon fuels (e.g., kerosene) are often used as coolant to absorb heat from the engine structure in a regenerative cooling system [1,2]. When hydrocarbon fuel with large molecules flows through the cooling channels, it absorbs heat from the combustor wall and its temperature may exceed the cracking point and pyrolysis occurs. The fuel is then decomposed into small molecular products such as methane, ethylene and hydrogen and so on before being injected into the combustor [3,4]. Many of previous works focused on combustion characteristics of single fuel components and fuel mixture, particularly representing products of pyrolysis is rarely studied. Therefore, it is necessary to investigate combustion characteristics of fuel mixture of hydrogen and small

\footnotetext{
* Corresponding author. No.15 Beisihuanxi Road, Institute of Mechanics, Chinese Academy of Sciences, Beijing, 100190, China.

E-mail address: fzhong@imech.ac.cn (F. Zhong).
} 


$\begin{array}{ll}\text { Nomenclature } \\ C_{D E S} & \text { Calibration constant used in DES model } \\ D & \text { Coefficient of mass diffusivity } \\ L_{t} & \text { Turbulent length scale } \\ \dot{m}_{F} & \text { Mass flow rate of fuel } \\ M a & \text { Mach number } \\ n & \text { Normal vector of cross section } \\ T & \text { Static temperature } \\ T_{0,1} & \text { Total temperature at the inlet } \\ T_{0,2} & \text { Mass-averaged total temperature at the outlet } \\ T_{a d} & \text { Adiabatic flame temperature } \\ t & \text { Flow time } \\ V & \text { Velocity vector and } \\ Y_{F} & \text { Mass fraction of fuel } \\ Y_{O} & \text { Mass fraction of oxidant } \\ Y_{O H} & \text { Mass fraction of OH species } \\ Y_{k} & \text { Dissipation of } k \\ \nabla & \text { Hamiltonian } \\ \eta & \text { Combustion efficiency } \\ \eta_{m i x} & \text { Mixing efficiency } \\ \rho & \text { Density } \\ k & \text { Turbulent kinetic energy } \\ \omega & \text { Specific dissipation rate } \\ \chi_{F, O} & \text { Cross-scalar dissipation rate } \\ & \end{array}$

molecular hydrocarbons for applications of realistic engine operation.

To study details of reaction flow in supersonic combustor, optical methods such as Schlieren Imaging or Laser Induced Fluorescence are attempted. However, the present optical methods are mainly applied in qualitative illustrations with limited visualization zones. Alternatively, numerical simulation with high order of accuracy is effective for the study of flow and reaction mechanism of supersonic combustion. Detached Eddy Simulation (DES) originally proposed by Spalart [5] combines advantages of Reynolds averaged N-S method (RANS) in the turbulent boundary layer and Large Eddy Simulation in the outer flow region and is considered an efficient method for resolving turbulent structures with relatively low computational costs. For example, Choi et al. [6] studied flow and combustion process of a scramjet combustor with hydrogen fuel via DES. The details of flow fields and characteristic frequencies are provided. It is concluded that comparing with RANS method, the DES is a very useful tool for scramjet studies and presents more detailed information of supersonic combustion. Vyasaprasath et al. [7] simulated planar mixing and turbulent combustion of hydrogen and air using DES model and obtained consistent results with the experimental data. The DES method is able to resolve the dynamics of reactive turbulent flow. Wang et al. [8] simulated reacting flow of the DLR supersonic combustor using a 19-step reaction model of hydrogen and a flamelet/progress variable model. The DES model can better simulate the turbulent transport processes and hence improve the accuracy of combustion simulation. Kummitha et al. [9-11] conducted the simulation of mixing and combustion of fuel and air in the DLR supersonic combustor. The authors used different passive technologies to improve the mixing and combustion efficiency.

Using DES method and a reduced kinetic mechanism, supersonic combustion of hydrogen and its mixture with methane and ethylene are considered in present works in order to compare the combustion properties for fuel mixture with pure hydrogen. The reduced mechanism with 25 species and 131 reaction steps is obtained from a detailed mechanism proposed by Wang [12] via a reduction method of directed relation graph with error propagation and sensitivity analysis (DRGEPSA) [13,14]. The present numerical method is validated by comparison of temperature profiles of hydrogen combustion with the experimental data reported by Gucrra et al. [15] for the DLR supersonic combustor. The supersonic combustion of mixture fuel of hydrogen, methane and ethylene is simulated and the effects of hydrocarbon components on flow and combustion properties are discussed. The present numerical work is expected to provide insights into combustion properties of fuel mixture of hydrogen and hydrocarbons with small molecules and to obtain better understanding of mechanisms of supersonic combustion.

\section{Computational method}

\section{The computational domain}

Fig. 1 gives configuration of a supersonic model combustor that has been experimentally tested at the German Aerospace Center (DLR) [15] as called as DLR supersonic combustor in many of previous literatures [16,17]. The channel has an inlet cross section of $40 \mathrm{~mm} \times 50 \mathrm{~mm}$, and the air has an inlet Mach number of 2.0 and an inlet static temperature of $340 \mathrm{~K}$. There is a wedge-shaped strut placed at the center of the combustor and is located $35 \mathrm{~mm}$ downstream of the combustor entrance. The strut has a length of $32 \mathrm{~mm}$ and a height of $6 \mathrm{~mm}$, where fuel is injected into the supersonic airflow at sonic velocity and with a static temperature of $250 \mathrm{~K}$.

The airstream and the fuel inlet boundary conditions are fixed with pre-given pressures and total temperatures. Slip wall is applied for the top and the bottom walls of the combustor to avoid resolving wall boundary layer as used in previous numerical work of $[18,19]$. The strut walls are treated as adiabatic and no-slip wall. The boundary conditions at the combustor outlet is set to be non-reflection since supersonic flow is assumed at the outlet. For the present study, several mesh sizes $(500 \times 300,600 \times 400,700 \times 500)$ are tested for the study of grid independency. As shown in Fig. 2, the time averaged temperature profiles at a streamwise distance of $\mathrm{x}=125 \mathrm{~mm}$ calculated with the mesh of $600 \times 400$ and $700 \times 500$ are very close to each other. Therefore, a mesh of $600 \times 400$ with a minimum grid spacing of $1.0 \times 10^{-6} \mathrm{~m}$ near the wall is chosen for the present study.

The Turbulence closure is achieved by means of DES (Detached eddy simulation) approach based on SST $k-\omega$ model $[20,21]$. The dissipation of $k$ is given by 


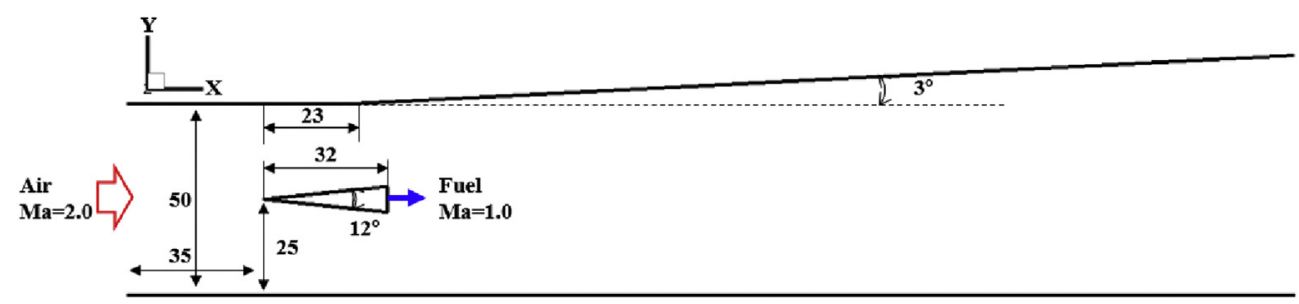

Fig. 1 - Configuration of the supersonic combustor (unit: $\mathrm{mm}$ ).

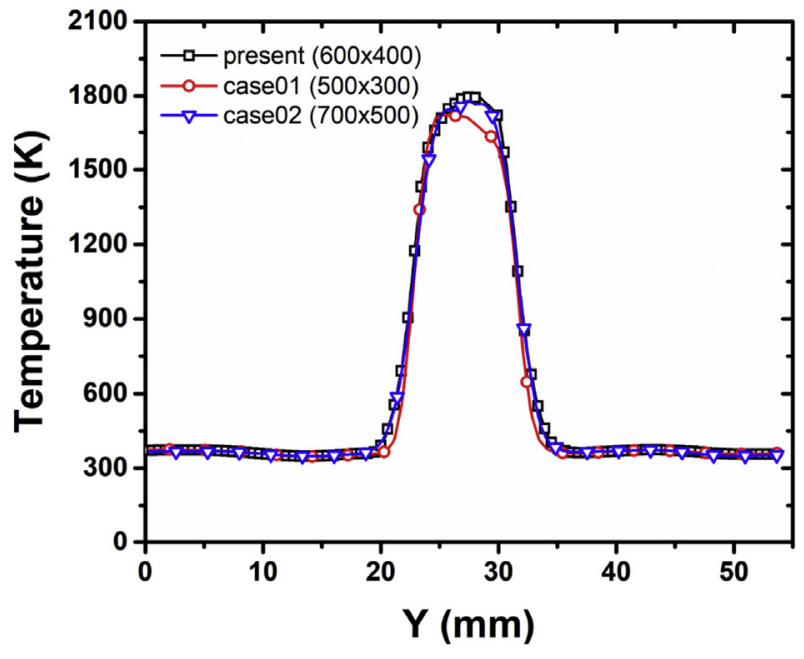

Fig. 2 - Time averaged temperature profiles calculated with different meshes.

$Y_{k}=\rho \beta^{*} k \omega F_{D E S}$

where $F_{D E S}$ is expressed as

$F_{D E S}=\max \left(\frac{L_{t}}{C_{D E S} \Delta_{\max }}, 1\right)$

$L_{t}=\frac{\sqrt{k}}{\beta^{*} \omega}$

where $C_{D E S}$ is a calibration constant of 0.61 and $\Delta_{\max }$ is the grid spacing which is the maximum length of quadrilateral cell.

The finite volume method is used to solve the flow transport equations, including continuity equation, momentum equation and scalar transport equations including energy and mixture fraction. The coupled algorithms have been used to solve the pressure-velocity coupling. The second-order upwind scheme is used to discretize the convective terms and the second-order center scheme is applied to calculate the diffusion terms. The specific heat of fuel/air mixture is obtained by the mass-weighted mixing law of all components. The polynomial fitting functions of temperature from NASA thermochemical polynomial data that are valid up to $5000 \mathrm{~K}$ is used to determine the specific heats of each species. The temporal terms are solved with second order implicit scheme. A time step of $10^{-6} \mathrm{~s}$ is set and the computations are conducted for 20 times of the flow characteristic time based on the combustor length and flow speed to ensure a statistically steady combustion flow has been established.

\section{Reacting mechanism}

The reduced mechanism of C1-C2 hydrocarbons proposed by Zhong et al. [22] is used in present work. It has 25 species and 131 elementary reactions, which are simplified from a detailed mechanism of Wang [12] with 71 species and 395 reaction steps via the DRGEPSA method. The detailed information about the reduced mechanism can be found in the literature [22]. The reduced mechanism is also valid for the combustion of hydrogen by comparing the predicted ignition delay time and laminar flame speed with the results provided by published experimental data or detailed kinetic mechanisms.

The present works use steady flamelet model to describe the combustion process and turbulent chemistry interactions. The reduced mechanism is implemented to generate flamelet library, and then to create the PDF database. The compressibility effect is included in the calculation of PDF database. The mass weight mixing law is used to calculate the flow property of fuel mixtures such as viscosity and thermal conductivity. Schmidt number is set to be 0.7 for calculation of species transport equations.

Except pure hydrogen, methane and ethylene are added to get fuel mixtures to study flow and combustion characteristics of hydrogen with addition of hydrocarbons. In this paper, two type of fuels are studied, fuel A: hydrogen, fuel B: mixture of hydrogen, ethylene and methane with a molar ratio of 1:1:1. The ratio choice partly refers to the result of cracking products

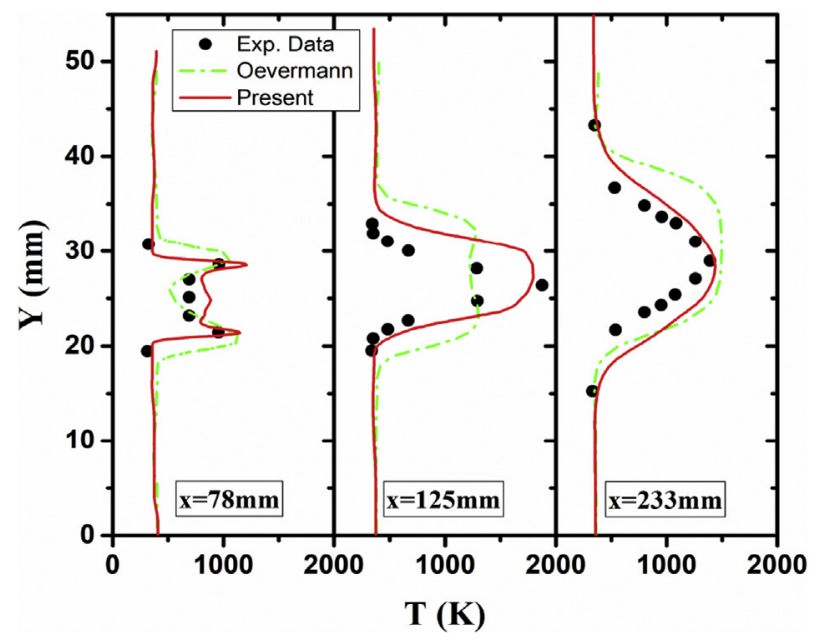

Fig. 3 - Temperature distribution curves at different streamwise location. 


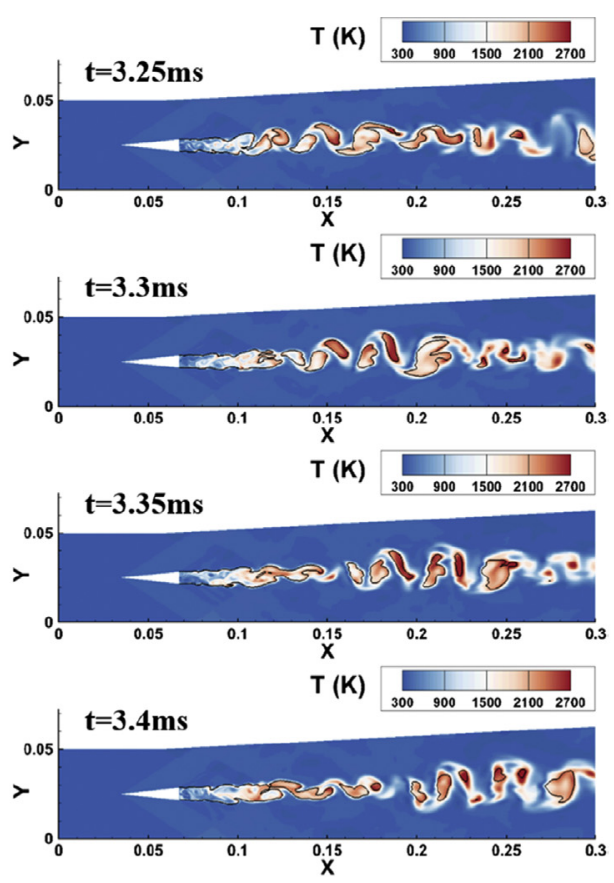

(a)
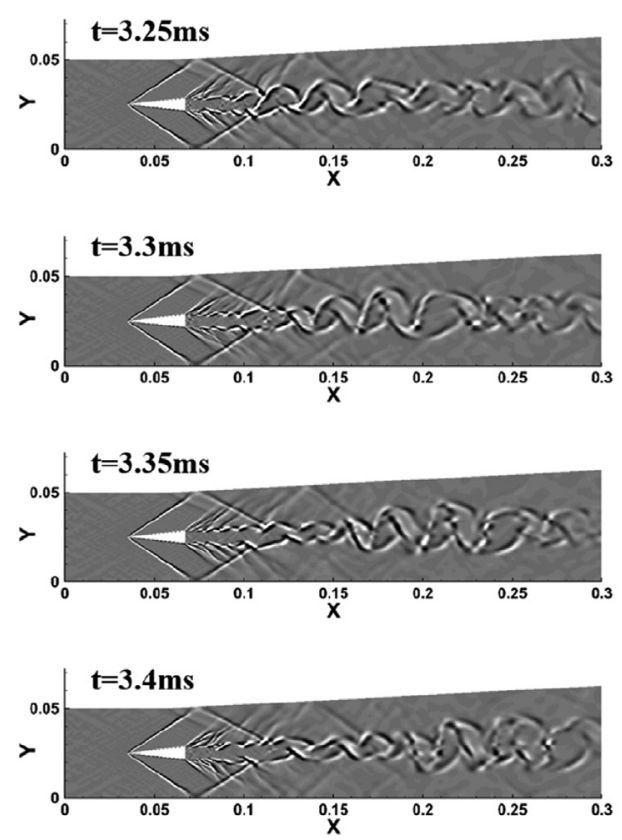

(c)

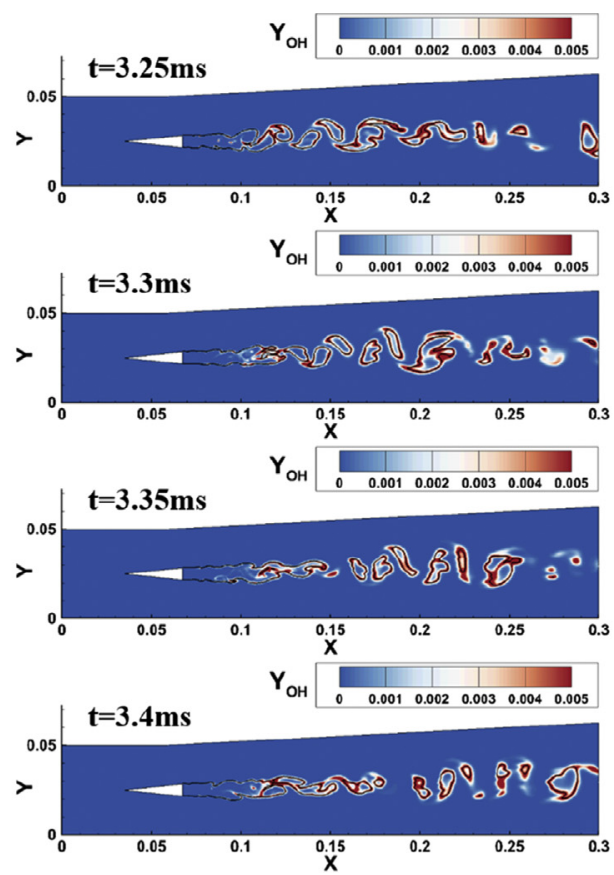

(b)
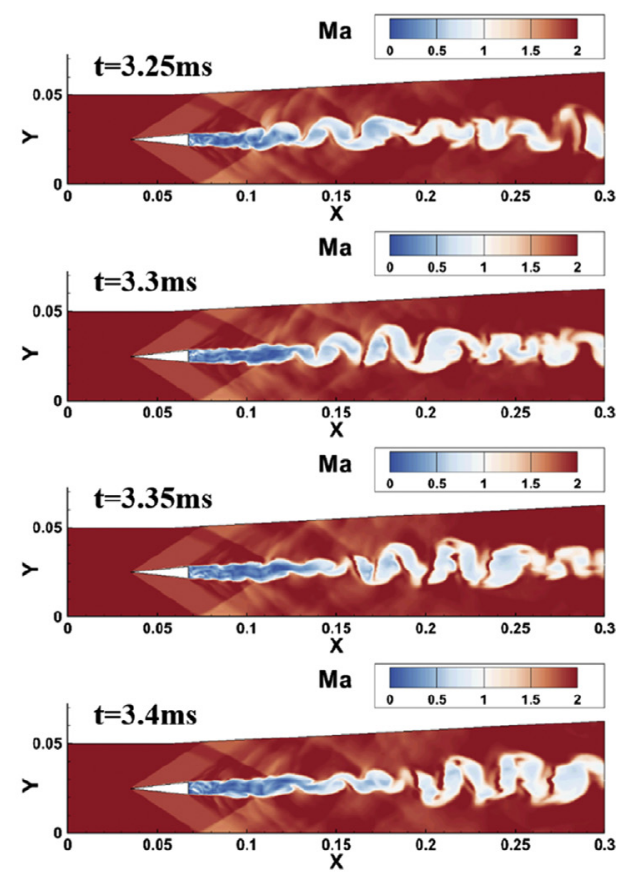

(d)

Fig. 4 - Contours of instantaneous temperature, mass fraction of $\mathrm{OH}$, shadow images and Mach number. (a) Temperature, (b) Mass Fraction of $\mathrm{OH}$, (c) Numerical shadow image, (d) Mach number.

of JP-7 fuel as described in reference [23]. The mixture fuel is fully pre-mixed before being injected into the combustor. The fuel inlet boundary condition is set with the pre-given pressure and total temperature. It is ensured that for fuel $\mathrm{A}$ and fuel $B$, the same fuel-to-air equivalence ratio is kept as well as the same fuel temperature.

\section{Results and discussion}

\section{Combustion of hydrogen}

Fig. 2 shows the time averaged temperature profiles of hydrogen (fuel A) at different streamwise locations in 

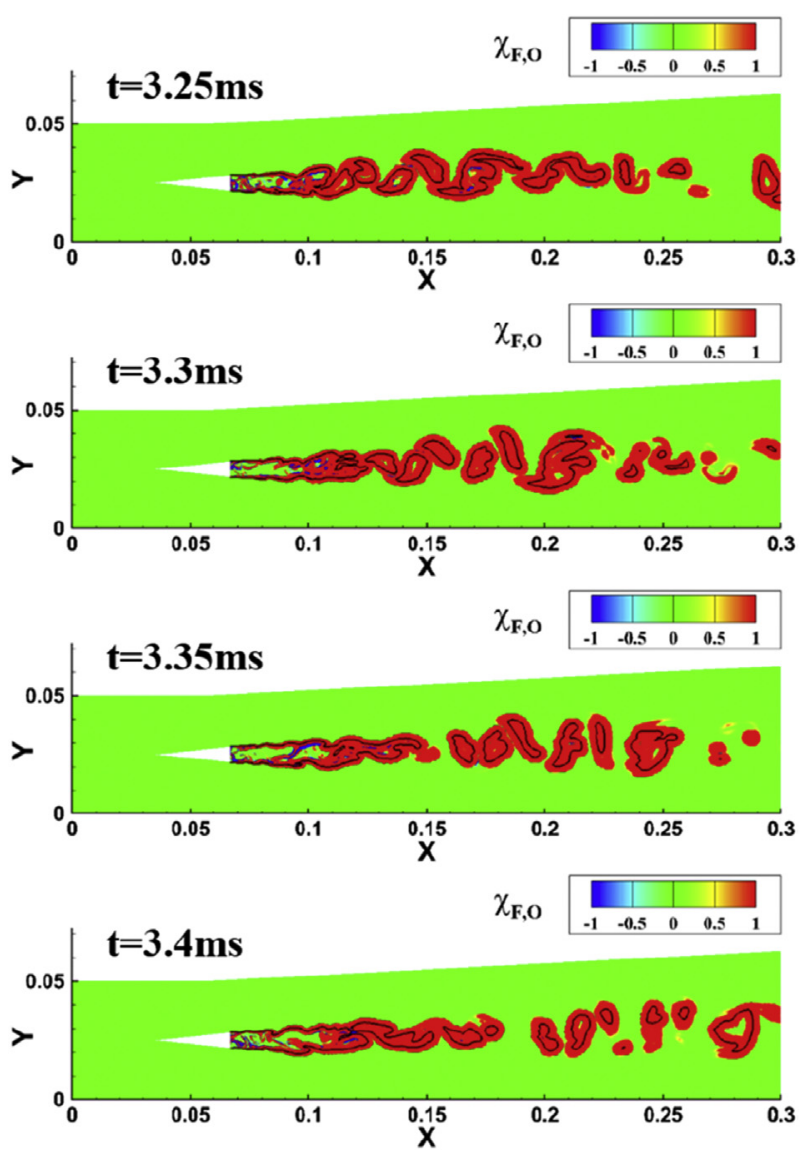

Fig. 5 - Contours of cross-scalar dissipation rate of flame.
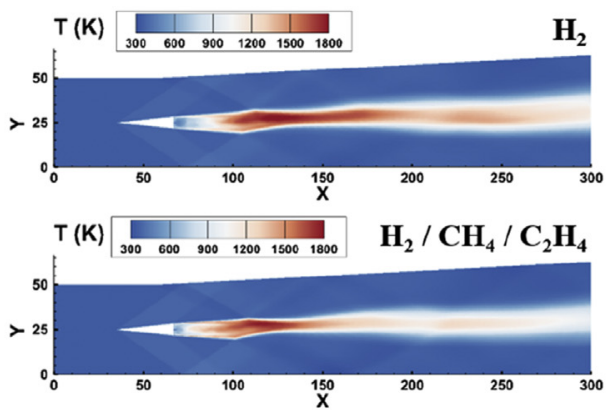

(a)
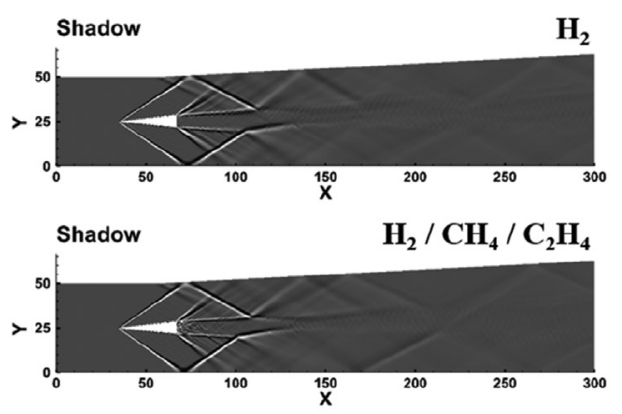

(c)

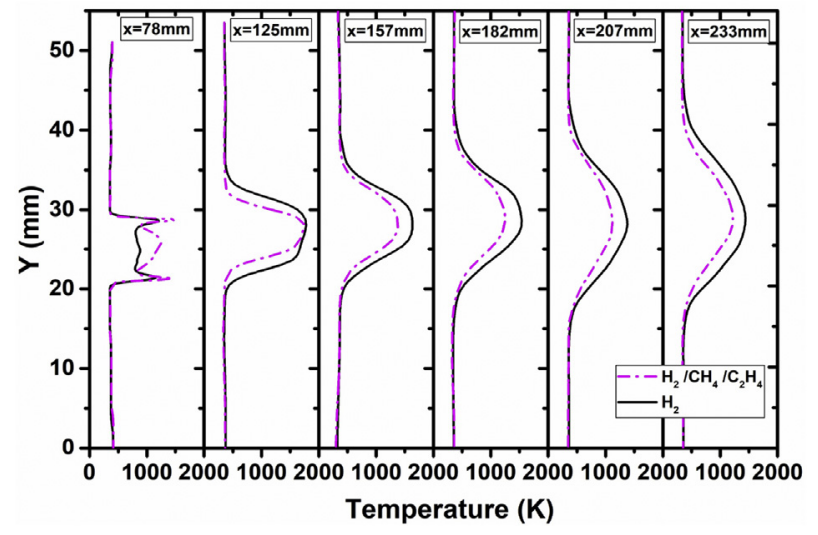

Fig. 7 - Temperature profiles at different streamwise locations for fuel $\mathrm{A}$ and $\mathrm{B}$.

comparisons with the experimental data of DLR [15]. The black circle symbols are the experimental data. The red solid lines are the present results and the green dash-dot lines are the RANS result from Oevermann et al. [18]. Compared to RANS method, DES method gives better results especially at downstream locations of $x=125 \mathrm{~mm}$ and $x=233 \mathrm{~mm}$ and agrees well with the experimental data.

As shown in Fig. 3, at $x=78 \mathrm{~mm}$, a location only $11 \mathrm{~mm}$ downstream of the strut, combustion occurs only in the shear layer of fuel/air mixing and the temperature profile shows two sharp peaks on top and bottom sides of the strut. As the mixing layer grows, combustion moves from the shear layer to the center zone of the combustor and the temperature reaches a maximum of about $1900 \mathrm{~K}$ at $\mathrm{x}=125 \mathrm{~mm}$. At further downstream locations, hydrogen is consumed quickly,
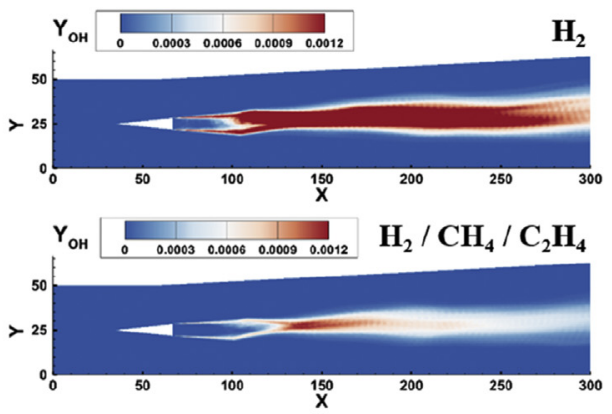

(b)
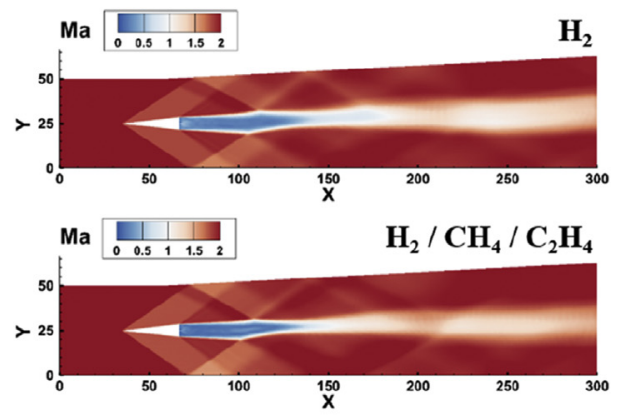

(d)

Fig. 6 - Contours of time-averaged temperature, mass fraction of $\mathrm{OH}$, shadow images and Mach number for fuel A and B. (a) Mean Temperature, (b) Mean Mass Fraction of $\mathrm{OH}$, (c) Mean Shadows, (d) Mean Mach Number. 
leading to decreasing in the combustion intensity and lower flow temperature.

Fig. 4 gives contours of instantaneous temperature, mass fraction of $\mathrm{OH}$, shadow images and Mach number at times of $3.25 \mathrm{~ms}, 3.3 \mathrm{~ms}, 3.35 \mathrm{~ms}$ and $3.4 \mathrm{~ms}$. The black lines in Fig. 4 (a) and (b) show the location of stoichiometric ratio of hydrogenair mixture. The $\mathrm{OH}$ radical is used to indicate the reaction zone and flame structure. As shown in Fig. 4 (b), the reacting zone is mainly distributed in the mixing shear layer and the shedding vortices downstream of the strut. The turbulent flow stretches flame and causes more air go into the reacting zone to have a more efficient mixing. Fig. 4 (c) and (d) clearly show shock structures caused by hydrogen/air mixing and combustion. The reflected shocks also affect the vortices downstream of the strut and change the flame shape.

Fig. 5 gives the cross-scalar dissipation rate defined as $\chi_{F, O}=-D \nabla Y_{F} \bullet \nabla Y_{O}$ at different times. The cross-scalar dissipation rate is often used to identify premixed and diffusion flames as discussed in the literatures [24,25]. With negative value, the cross-scalar dissipation rate indicates premixed combustion and with positive value, it indicates diffusion combustion. In Fig. 5, the black lines show the location of stoichiometric ratio of fuel-air mixture. Fig. 5 clearly shows that pre-mixed flame is located just downstream of the strut and in the wake region of the strut. As fuel goes further downstream, flame is mainly in diffusion pattern and located around the shedding vortices.

\section{Combustion of mixtures of hydrogen and hydrocarbons}

For a regeneratively cooled supersonic combustor, hydrogen and hydrocarbon mixtures as cracking products of largemolecular fuels are injected into combustor as discussed in the "introduction" part. The addition of hydrocarbons such as ethylene and methane changes physical and chemical properties of fuel and affects flame distribution and combustion efficiency. Therefore, in this part, combustion of fuel mixture of hydrogen, ethylene and methane with a molar ratio of 1:1:1 (fuel B) is studied at the same fuel to air equivalence ratio as hydrogen.

Contours of time-averaged (the averaging time is $5 \mathrm{~ms}$ with 500 samples) temperature, mass fraction of $\mathrm{OH}$, numerical shadow image and Mach number are given in Fig. 6. As shown in Fig. 6 (a), the high-temperature region of hydrogen combustion is quite different from that of fuel $B$ with hydrocarbon additions. The combustion intensity of hydrogen is stronger than the fuel $\mathrm{B}$ and the zone of high temperature is wider. Fig. 7 give the temperature curves at different streamwise locations. At $x=78 \mathrm{~mm}$, a location just downstream of the strut injection, the temperature profiles of both fuels show peaks in the fuel/air mixing shear layer regions at upper and lower sides of the strut. At locations further downstream, the temperature profiles for both fuel give a single peak in the center region and the peak value of hydrogen is obviously higher than that of fuel $\mathrm{B}$. The more intensive combustion of hydrogen can also be explained by comparing the ignition delay time and flame speed of the two fuels. Fig. 8 (a) and (b) plot the ignition delay time and laminar flame speed of fuel A and B at varied fuel/air equivalence ratios. The calculation of ignition delay time and flame speed reveals that fuel mixture of hydrogen and hydrocarbons has considerably larger delay time and smaller flame speed, that contributes to the weakened flame zone and lower combustion efficiency.

Fig. 9 give contours of instantaneous temperature, mass fraction of $\mathrm{OH}$, shadows and Mach number of different fuels at $t=3.25 \mathrm{~ms}$ and $t=3.35 \mathrm{~ms}$. Similar to the discussion in Fig. 5 for hydrogen, turbulent flow stretches flame in the shear layer and the wake regions. Reaction zones are separated from the main flow, forming several isolated combustion "island". With addition of methane and ethylene, the interaction between turbulence and combustion becomes weaker and the isolated combustion islands are less and smaller. As shown in Fig. 9 (a), the high temperature region of fuel $A$ is obviously larger than that of fuel B, indicating higher combustion efficiency for fuel A. The OH contours given in Fig. 9 (b) show that for fuel B, the flame zone becomes smaller and the flame base moves further downstream of the strut. For both fuels, flame kernels are observed to be related to the vortices downstream of the strut and for fuel B, the flame is weakened with much smaller and sparse distribution of flame kernels. Fig. 9 (c) plots numerical schlieren for both fuels. It is found that flame and vortices downstream of the strut are strongly affected by the shock waves reflected from the upper and the bottom walls. For

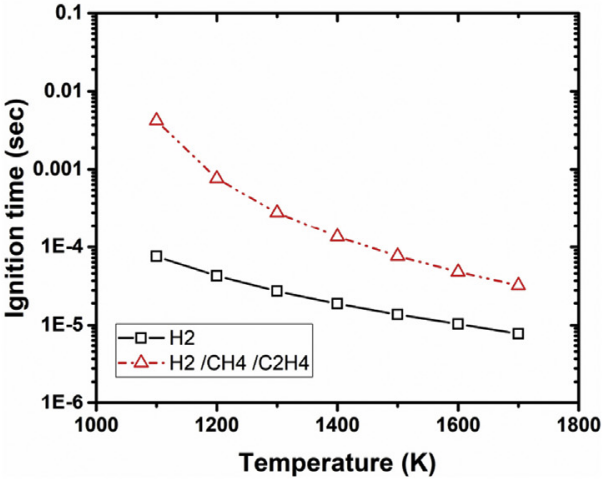

(a)

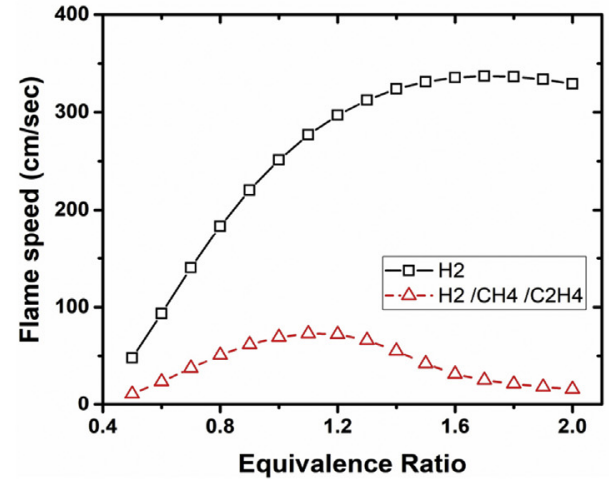

(b)

Fig. 8 - Ignition delay time and laminar flame speed at 1 atm for fuel A and B. (a) Ignition delay time, (b) Laminar Flame Speed. 


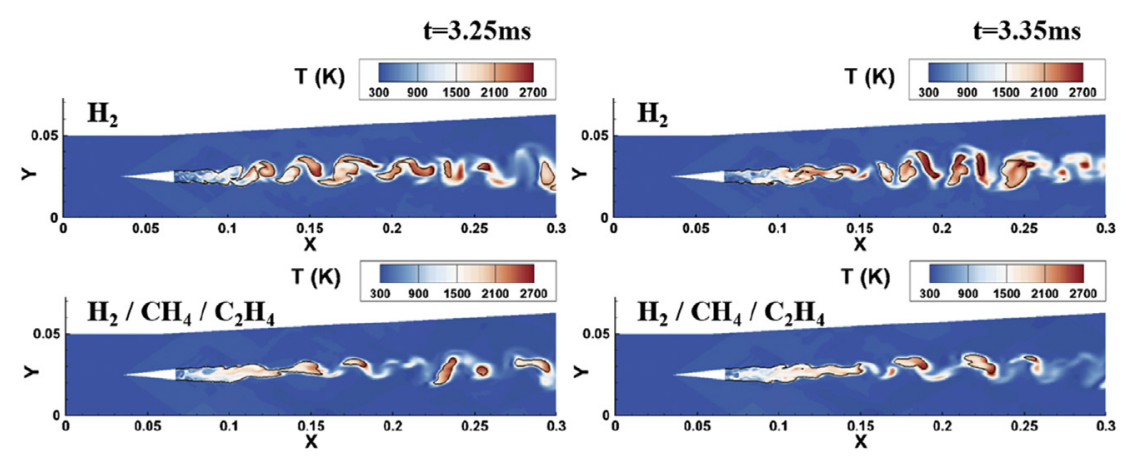

(a)

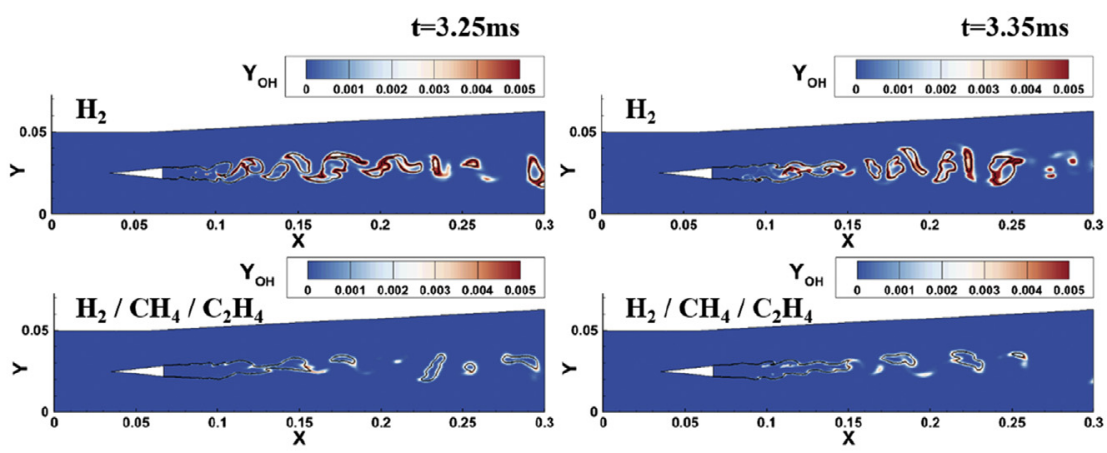

(b)

$t=3.25 \mathrm{~ms}$

$\mathrm{t}=3.35 \mathrm{~ms}$
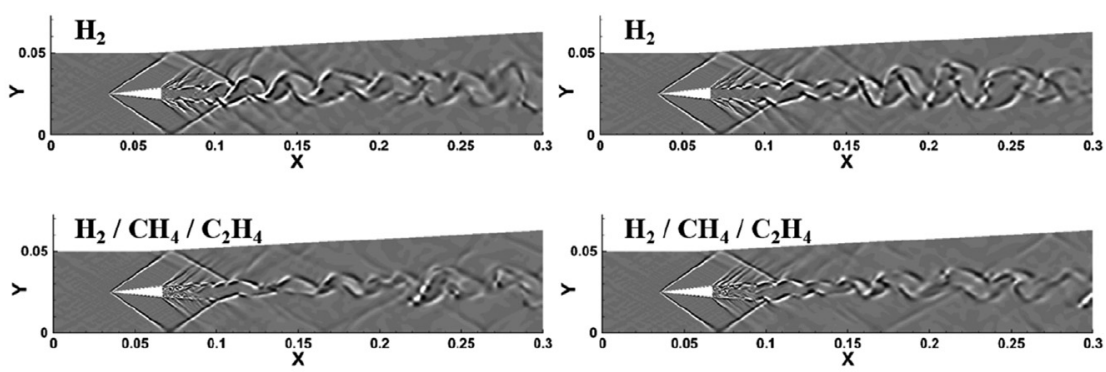

(c)

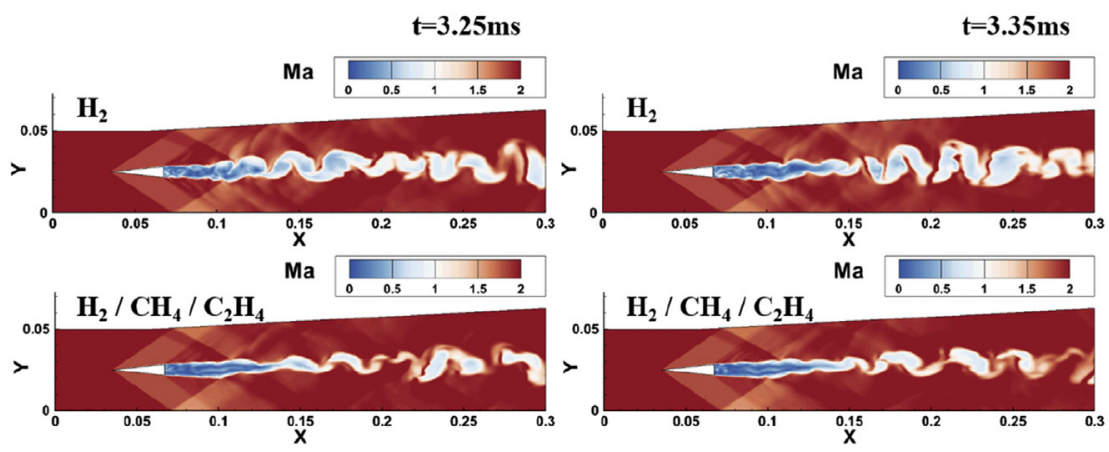

(d)

Fig. 9 - Contours of instantaneous temperature, mass fraction of $\mathrm{OH}$, numerical shadow and Mach number for fuel A and B at $t=3.25 \mathrm{~ms}$ and $t=3.35 \mathrm{~ms}$. (a) Temperature, (b) Mass Fraction of $\mathrm{OH}$, (c) Shadows, (d) Mach Number.

hydrogen fuel, the shock-combustion interaction is stronger due to more heat releasing and larger reaction zone of hydrogen.

Distributions of combustion efficiency and mixing efficiency along the streamwise direction are drawn in Fig. 10.
The combustion efficiency defined as the ratio of total temperature differences as defined in the literature [26]:

$\eta=\frac{\mathrm{T}_{02}-\mathrm{T}_{01}}{\mathrm{~T}_{a d}-\mathrm{T}_{01}}$ 


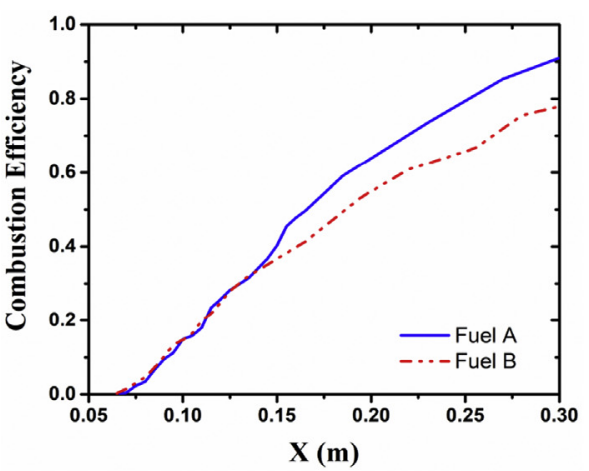

(a)

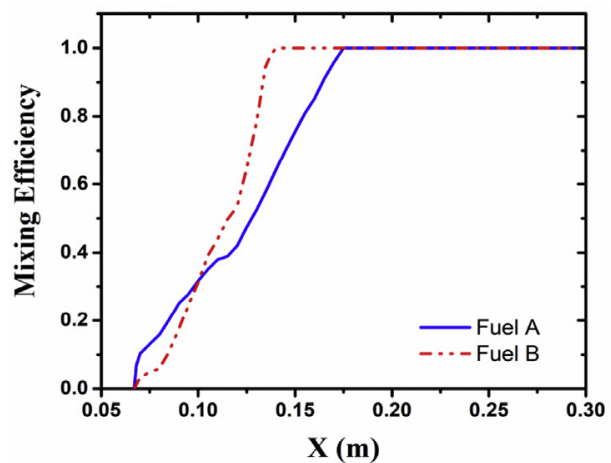

(b)

Fig. 10 - Distributions of combustion efficiency and mixing efficiency for fuel A and B. (a) Combustion efficiency, (b) Mixing efficiency.

Table 1 - The combustion efficiency and mixing length. Combustion efficiency at the exit

\begin{tabular}{lcl}
\multicolumn{3}{c}{ at the exit } \\
\hline Fuel A & 0.91 & $108 \mathrm{~mm}$ \\
Fuel B & 0.78 & $73 \mathrm{~mm}$ \\
\hline
\end{tabular}

where $T_{02}$ is the mass-averaged total temperature at the combustor outlet and $T_{01}$ is the mass-averaged total temperature at the inlet and $T_{a d}$ is the adiabatic flame temperature of the fuel/air mixture.

The mixing efficiency is defined as follows according to the literature [27]:

$\eta_{\text {mix }}=\frac{\dot{m}_{F, \text { mix }}}{\dot{m}_{F}}=\frac{\int \rho Y_{M}(V \bullet n) d A}{\int \rho Y_{F}(V \bullet n) d A}$

The $Y_{M}$ was defined as

$Y_{M}=\left\{\begin{array}{l}Y_{F} \text { if } Y_{F} \leq Y_{T} \\ Y_{T} \text { if } Y_{F}>Y_{T}\end{array}, \quad Y_{T}=Y_{O}\left(\frac{Y_{F}}{Y_{O}}\right)_{s t}\right.$

where, $Y_{\text {air }}$ is the mass fraction of air and $Y_{F}$ is the mass fraction of fuel, and $V$ is velocity vector and $n$ is normal vector of cross section. The subscript of st indicates the stoichiometric ratio. The mixing length is defined as the length over which the mixing efficiency increases from 0 to 1.

For hydrogen combustion, the combustion efficiency at the combustor outlet is 0.91 , while, for fuel mixture, the combustion efficiency is 0.78 as listed in Table 1 . For fuel $\mathrm{A}$, the mixing length is $108 \mathrm{~mm}$ and it is $73 \mathrm{~mm}$ for fuel $\mathrm{B}$ since for hydrogen, the injection velocity is about $1200 \mathrm{~m} / \mathrm{s}$, which is much higher than that of the fuel mixture $(430 \mathrm{~m} / \mathrm{s})$.

\section{Conclusions}

In order to investigate the combustion characteristics of mixed fuels, supersonic flow and combustion of strut injections of hydrogen and its mixture with hydrocarbons are simulated with DES method and reduced kinetic mechanism of C2 and steady flamelet model. The models are verified by comparing the calculated temperature profiles with experimental data of DLR supersonic combustor. The flow fields and radical distributions clearly show flame structure and turbulent vortices downstream of the strut injector. The flame is strongly stretched by vortices and shock waves. With addition of methane and ethylene, combustion intensity is weakened and reaction zone and flame shapes change significantly. The flame zones move further downstream of the strut and become wider than that of hydrogen. The maximum flow temperature at chamber exit decreases by about $200 \mathrm{~K}$. The analysis of chemical reaction kinetics that fuel mixture of hydrogen and hydrocarbons has considerable larger ignition delay time and smaller flame speed. The combustion efficiency of hydrogen and hydrocarbons mixture is 0.78 , while, for pure hydrogen, the combustion efficiency is 0.91 .

\section{Acknowledgement}

This work is supported by the National Natural Science Foundation of China (Grants 91441102 and 11672307) and Youth Innovation Promotion Association, Chinese Academy of Sciences.

\section{R E F E R E N C E S}

[1] Lander H, Nixon AC. Endothermic fuels for hypersonic vehicles. J Aircraft 1971;8(4):200-7. https://doi.org/10.2514/ 3.44255.

[2] Wang N, Zhou J, Pan Y, Wang H. A parametric experimental study on the heat transfer characteristics of supercritical kerosene in active cooling channels of scramjets. Adv Mater Res 2013;774-776:252-7. https://doi.org/10.4028/ www.scientific.net/AMR.774-776.252.

[3] Fan X, Zhong F, Yu G, Li J, Sung CJ. Catalytic cracking of China no. 3 aviation kerosene under supercritical conditions. In: 44th AIAA/ASME/SAE/ASEE joint propulsion conference \& exhibit; 2008. https://doi.org/10.2514/6.2008-5130. AIAA 20085130.

[4] Zhao G, Song W, Zhang R. Effect of pressure on thermal cracking of China RP-3 aviation kerosene under supercritical 
conditions. Int J Heat Mass Tran 2015;84:625-32. https:// doi.org/10.1016/j.ijheatmasstransfer.2015.01.059.

[5] Spalart PR, Jou WH, Strelets M, Allmaras SR. Comments on the feasibility of LES for wings, and on a hybrid RANS/LES approach, vol. 1; 1997. p. 4-8. Advances in DNS/LES.

[6] Choi JY, Yang V, Ma F, Won SH, Jeung IS. DES combustion modeling of a scramjet combustor. In: 42nd AIAA/ASME/SAE/ ASEE joint propulsion conference \& exhibit; 2006. https:// doi.org/10.2514/6.2006-5097. AIAA, 2006-5097.

[7] Vyasaprasath K, Oh S, Kim KS, Choi JY. Numerical studies of supersonic planar mixing and turbulent combustion using a detached eddy simulation (DES) model. Int J Aeronaut Sci Aero Space Sci 2015;16(4):560-70. https://doi.org/10.5139/ IJASS.2015.16.4.560.

[8] Wang H, Shan F, Ying P, Hou L, Niu J. IDDES simulation of hydrogen-fueled supersonic combustion using flamelet modeling. Int J Hydrogen Energy 2015;40(1):683-91. https:// doi.org/10.1016/j.ijhydene.2014.10.124.

[9] Kummitha OR. Numerical analysis of passive techniques for optimizing the performance of scramjet combustor. Int J Hydrogen Energy 2017;42(15):10455-65. https://doi.org/ 10.1016/j.ijhydene.2017.01.148.

[10] Kummitha OR, Suneetha L, Pandey KM. Numerical analysis of scramjet combustor with innovative strut and fuel injection techniques. Int J Hydrogen Energy 2017;42(15):10524-35. https://doi.org/10.1016/ j.ijhydene.2017.01.213.

[11] Kummitha OR. Numerical analysis of hydrogen fuel scramjet combustor with turbulence development inserts and with different turbulence models. Int J Hydrogen Energy 2016;42(9):6360-8. https://doi.org/10.1016/ j.ijhydene.2016.10.137.

[12] Wang H, Laskin A. A comprehensive kinetic model of ethylene and acetylene oxidation at high temperatures. Progress Report for an AFOSR New World Vista Program. Department of Mechanical Engineering, University of Delaware; 1998.

[13] Pepiot-Desjardins P, Pitsch H. An efficient error-propagationbased reduction method for large chemical kinetic mechanisms. Combust Flame 2008;154(1):67-81. https:// doi.org/10.1016/j.combustflame.2007.10.020.

[14] Niemeyer KE, Sung CJ, Raju MP. Skeletal mechanism generation for surrogate fuels using directed relation graph with error propagation and sensitivity analysis. Combust Flame 2010;157(9):1760-70. https://doi.org/10.1016/ j.combustflame.2009.12.022.

[15] Guerra R, Waidmann W, Laible C. An experimental investigation of the combustion of a hydrogen jet injected parallel in a supersonic air stream. In: Aiaa, International Aerospace planes conference, Orlando; 1991. p. 453-4. https://doi.org/10.2514/6.1991-5102. 02-06 December. DLR.

[16] Fureby C, Fedina E, Tegnér J. A computational study of supersonic combustion behind a wedge-shaped flameholder. Shock Waves 2013;24(1):41-50. https://doi.org/10.1007/ s00193-013-0459-2.

[17] Berglund M, Fureby C. LES of supersonic combustion in a scramjet engine model. Proc Combust Inst 2007;31(2):2497-504. https://doi.org/10.1016/j.proci.2006.07.074.

[18] Oevermann M. Numerical investigation of turbulent hydrogen combustion in a SCRAMJET using flamelet modeling. Aero Sci Technol 2000;4(7):463-80. https://doi.org/ 10.1016/S1270-9638(00)01070-1.

[19] Fan Z, Liu W, Sun M, Wang Z, Zhuang F, Luo W. Theoretical analysis of flamelet model for supersonic turbulent combustion. Sci China Technol Sci 2012;55(1):193-205. https://doi.org/10.1007/s11431-011-4659-7.

[20] Menter FR. Two-equation eddy-viscosity turbulence models for engineering applications. AIAA J 2012;32(8):1598-605. https://doi.org/10.2514/3.12149.

[21] Strelets M. Detached eddy simulation of massively separated flows. In: 39th Aerospace Sciences Meeting and Exhibit; 2001. https://doi.org/10.2514/6.2001-879. AIAA 2001-0879.

[22] Zhong F, Ma S, Zhang X, Sung CJ, Niemeyer KE. Development of efficient and accurate skeletal mechanisms for hydrocarbon fuels and kerosene surrogate. Acta Mech Sin 2015;31(5):732-40. https://doi.org/10.1007/s10409-015-0434-5.

[23] Leylegian J, Chinitz W. Investigation of short contact time reactors for regeneratively-cooled hypersonic vehicles. J Propul Power 2012;28(2):412-22. https://doi.org/10.2514/ 1.B34118.

[24] Yamashita H, Shimada M, Takeno T. A numerical study on flame stability at the transition point of jet diffusion flames. Symp Combust Proc 1996;26(1):27-34. https://doi.org/ 10.1016/S0082-0784(96)80196-2.

[25] Favier V, Vervisch L. Edge flames and partially premixed combustion in diffusion flame quenching. Combust Flame 2001;125(1):788-803. https://doi.org/10.1016/S0010-2180(00) 00242-X.

[26] Heiser W, Pratt D, Daley D, Mehta U. Hypersonic airbreathing propulsion. Am Inst Aeronaut Astronaut 1994:331-2. https:// doi.org/10.2514/4.470356.

[27] Eklund D, Baurle R, Gruber M. Numerical study of a scramjet combustor fueled by an aerodynamic ramp injector in dualmode combustion. In: 39th Aero Sci Meet Exhib; 2001. https:// doi.org/10.2514/6.2001-379. AIAA 2001-0379. 